\title{
Programa de treinamento de habilidades sociais para a prática do futebol
}

\author{
Social skills training program for soccer practice
}

Giovana Munhoz da Rochaa ${ }^{[a]}$ Mariana Fernanda Bertassoni Monteiro ${ }^{[b]}$

\footnotetext{
${ }^{[a]}$ Professora adjunta na Faculdade Evangélica do Paraná e na Universidade Tuiuti do Paraná (UTP), Doutora em Psicologia Clínica pelo Departamento de Psicologia da Universidade de São Paulo (USP), Curitiba, PR- Brasil, e-mail: gicarocha@ uol.com.br

${ }^{[b]}$ Psicóloga pela Faculdade Evangélica do Paraná (FEPAR), Curitiba, PR - Brasil, e-mail: marifbmonteiro@gmail.com

Recebido: 06/04/2010 Received: 04/06/2010

Aprovado: 29/09/2010 Approved: 09/29/2010
}

\section{Resumo}

O presente estudo consistiu no desenvolvimento de um programa de treinamento em habilidades sociais, com intervenções psicológicas em grupo, voltado para o esporte, especificamente o futebol. Os participantes eram atletas juvenis (14 a 16 anos), de um Clube profissional da cidade Curitiba. Todos eram estudantes e parte deles moravam no alojamento do Clube e outra parte em suas residências. Ocorreram aplicações de pré-teste e pós-teste de um inventário que avaliou as habilidades sociais dos pesquisados, para delimitar os escores destes antes e depois da intervenção. 0 programa de habilidades sociais consistiu em 11 sessões, com duração de 1 hora e 30 minutos cada, duas vezes por semana, com vivências das principais habilidades necessárias para o desenvolvimento da competência social. As vivências foram adaptadas ao contexto do esporte. 0 programa revelou-se uma ferramenta adicional eficaz no processo de formação do atleta, apontando para a presença da psicologia como cada vez mais importante no esporte; uma vez que os atletas recebem treinamentos técnicos e táticos, recebem apoio médico, fisioterápico e nutricional, mas muitas vezes não contam com o acompanhamento psicológico, o que poderá ser no futuro um fator determinante para o sucesso profissional. Os resultados desse estudo sugerem ser possível propor um programa de Habilidades Sociais para o futebol e considerá-lo válido para a formação do atleta, pois o ajudará em seu desenvolvimento pessoal, o que invariavelmente o auxiliará em seu rendimento esportivo.

Palavras-chave: Habilidades sociais. Competência social. Futebol. Psicologia do esporte.

\section{Abstract}

The study presented here consists of the development of a social skills training program, with group psychological interventions, focusing on sports practice, specifically soccer. Participants were juvenile athletes, with ages ranging from 14 to 16 years old, from a professional team of Curitiba city. They all were students and some of them used to live in the team lodging, others lived with their own families. Pre and post tests from an inventory on social skills were ministrated to assess the participants' scores before and after the intervention. The social skills training program consisted of 11 sessions of one and a half hour each, held twice a week. The sessions focused on activities for each social skill deemed necessary to the development of a social competence. The program was adapted to sports context. The training program revealed 
itself as an effective additional tool in athlete's constitutional process, pointing to the presence of psychology as an increasingly relevant item in sports; the athletes received technical and tactical training, and are submitted to medical, nutritional and physiotherapeutical support, but they are many times not offered any psychological support, what may play a major role in their professional outcome. The results of this study suggest that it is possible to propose a social skills training program for juvenile soccer players and consider such training as invaluable to the athletes' development processes once it may help assist them in their personal growth, which in turn, will invariably boost their sports performance.

Keywords: Social skills. Social competence. Soccer. Sports psychology.

\section{Introdução}

Sabe-se que no Brasil, mais do que na maioria dos outros países, o futebol arrebata milhões de torcedores e milhares de jovens atletas que sonham com um futuro de sucesso e muitas vezes, sustento para suas famílias.

Segundo Stemme (1981) como citado por Brandão (2004) o futebol é hoje o esporte dominante no mundo por estar em todas as culturas e regiões. Campos (2004) afirma que o sucesso no futebol está ligado à integração das habilidades motoras e cognitivas, pois a dinâmica do jogo demanda situações em que o jogador precisa tomar decisões apropriadas e executá-las corretamente.

Habilidades Sociais podem ser definidas como comportamentos específicos que um indivíduo apresenta ao desempenhar uma tarefa social de forma competente (Gresham, 2002).

Estudos sobre o desenvolvimento de habilidades sociais em vários campos mostram haver uma significativa relação entre a presença destas habilidades e o sucesso acadêmico, profissional e afetivo (Gresham, Cook, Kern, Barreras, Thornton \& Crews, 2008). Sendo assim, pode-se supor que as habilidades sociais também podem funcionar como ferramenta para uma melhor adaptação às mudanças que o contexto esportivo proporciona.

Del Prette e Del Prette (2005) afirmam que a intervenção com crianças e/ou adolescentes se justifica pela plasticidade do comportamento social apresentado nestas fases de desenvolvimento, uma vez que na fase adulta é mais custoso tanto financeiramente quanto emocionalmente para a pessoa. Pesquisas atuais apresentam resultados positivos de treinamentos de habilidades sociais com crianças portadoras de distúrbios de comportamento disruptivo (Preece \& Mellor, 2009), que passaram a apresentar taxas cada vez mais baixas de comportamentos inadequados em casa e na escola. Harrell, Marcer e DeRosier (2009) apresentaram um estudo no qual adolescentes participaram de um programa construído para melhorar o ajustamento social, emocional e comportamental. Ao fim do mesmo constatou-se que ocorreram mudanças significativas, ou seja, melhora quanto ao autoconceito e autoeficácia social, bem como observou-se diminuição quanto aos problemas internalizantes.

Uma parte significativa das habilidades sociais refere-se a um grupo de comportamentos relacionados à resolução de problemas interpessoais (Del Prette \& Del Prette, 2005). É possível supor, partindo de algumas características conhecidas sobre o jogo de futebol na atualidade (ex.: concorrência entre jogadores por vagas nos times, concorrência quanto à titularidade em um time, disputas homem a homem durante as partidas), que o atleta considerado como bem sucedido deva ter uma boa capacidade de resolução de problemas. Sabe-se que treinamentos em habilidades sociais são especialmente eficazes para o desenvolvimento e aprimoramento da capacidade de resolução de problemas (Dereli, 2009). Porém, na literatura não se encontram disponíveis estudos que apresentem dados acerca destes comportamentos em atletas, tampouco especificamente sobre jogadores de futebol. Na realidade há poucos estudos que envolvam práticas de esporte em grupo e habilidades sociais, contudo Howie et al. (2010) desenvolveram um trabalho do qual podem ser retiradas algumas conclusões interessantes. Os autores 
perceberam existir uma relação importante entre a participação de crianças em grupos esportivos e a diminuição de problemas comportamentais. Eles concluíram que crianças que fazem esportes com frequência regular possuem taxas mais elevadas de habilidades sociais do que as crianças que não o fazem.

Em face da escassez de estudos que versem sobre a realidade brasileira das habilidades sociais daqueles que pretendem ser jogadores profissionais de futebol, surgiu então o interesse em estudar sobre a possível relação entre o desempenho esportivo no futebol e as habilidades sociais do atleta.

\section{Revisão de literatura}

No Brasil, a história do futebol teve início em 1895 e desde então esta modalidade esportiva tem revelado grandes jogadores, sendo que atualmente pode-se afirmar que é o país que mais exporta talentos para vários países da Europa, Ásia e América do Norte.

Em seu desenvolvimento e constituição enquanto campo esportivo, o futebol teve diversas fases. Segundo Corrêa (2004) a fase atual compreende além do esporte, um vasto campo de negócios. Os grandes Clubes funcionam como empresas e estão em constante busca de aperfeiçoamento da competência de quem mantêm diretamente seu negócio, neste caso os atletas.

$\mathrm{Na}$ perspectiva de estimular o desenvolvimento de competências para atletas, Nideffer (1992) citado por Brandão (2004) defende que no esporte contemporâneo o que tem feito mais diferença entre as equipes é sua preparação psicológica, uma vez que os treinamentos e capacitação de talentos são eficazes e tendem a igualar as equipes. Brandão (2004) complementa explicando que principalmente no esporte de alto rendimento, que é o caso do futebol, o treinamento psicológico se faz mais importante, uma vez que pode se tornar o diferencial para o sucesso.

Recentemente, Weinberg e Gould (2006), expuseram o Treinamento de Habilidades Psicológicas (THP), que se caracteriza pela prática sistemática e consistente de habilidades psicológicas, que tem por objetivo manter e focalizar a concentração, regular os níveis de ativação, aumentar a confiança e manter a motivação do atleta.
Os autores (Weinberg \& Gould, 2006) colocam que há várias formas de desenvolver um THP, mas que ele deve sempre seguir três passos. 0 primeiro é a fase da educação, ou seja, explicitar ao atleta a importância do treinamento psicológico, por meio de exemplos, tais como, o papel da ansiedade no desempenho final da modalidade, o nível que ela deve estar para se agregar sucesso. A segunda fase é composta da aquisição, que apresenta estratégias e técnicas para o aprendizado dessas habilidades psicológicas e a última fase é a prática, que busca autonomizar as habilidades, integrá-las com seu desempenho esportivo e simulação de uma situação real de competição em que a habilidade é necessária. Expõem que o treinamento deve ocorrer de uma a duas vezes na semana, antes e depois dos treinos esportivos.

Preece e Mellor (2008) discorrem sobre a eficácia de programas de habilidades sociais com curta e longa duração, em que aparentemente os dois modos repercutem positivamente, mas em decorrência da prática clínica, os programas com menos duração se mostram mais adaptativos, com tendência da taxa de abandono e desmotivação caírem.

Samulski e Parreiras (2009) afirmam que para o esporte de rendimento é necessário ter liderança, autodomínio, extroversão e comunicação social. Ainda sobre as habilidades do atleta que vão além das físicas, Pérez (1996) como citado por Soto (2000), afirma que capacidade do indivíduo de resolver problemas, enfrentar situações, organizar, planejar, transformar o meio, sentir-se competente, ter conhecimento dos processos e atitudes, fazem parte de suas habilidades motoras e cognitivas.

Ao mesmo tempo em que há uma vertente que defende a influência do estado emocional no esporte, Moreno (2007) afirma que o esporte pode auxiliar o desenvolvimento da personalidade por exigir uma melhor preparação psicológica para a sua prática, o que preconiza o aumento da confiança, da perseverança, da motivação intrínseca e da segurança, níveis variados de disciplina que facilitem a convivência em meio a grupos sociais distintos.

Corroboram com esse pensamento os autores Samulski e Parreiras (2009) quando expõem que o esporte pode funcionar positivamente sobre o desenvolvimento de comportamentos sociais, na estabilidade emocional e motivacional, bem como na autodisciplina. 
Segundo Del Prette e Del Prette (2005, p. 31-33), "o termo Habilidades Sociais, geralmente utilizado no plural, aplica-se à noção de diferentes classes de comportamentos sociais no repertório de um indivíduo, que contribuem para a competência social, favorecendo um relacionamento saudável e produtivo com as demais pessoas". E complementam discorrendo sobre o tema competência social, que seria a consequência das habilidades sociais, ou seja, o que elas produzem na vida do sujeito. "Capacidade de articular pensamentos, sentimentos e ações em função de objetivos pessoais e de demandas da situação e da cultura, gerando consequência positivas para o indivíduo e para sua relação com as demais pessoas".

Sabe-se também, a partir de inúmeras pesquisas na área (Gaspar, Matos, Ribeiro \& Leal, 2006; Oliveira, 2005) que pessoas consideradas socialmente competentes possuem mais qualidade de vida, conseguem melhores empregos, são menos acometidas por distúrbios ligados ao stress e à ansiedade e têm melhor desempenho acadêmico.

Sendo assim, somando-se isto às informações já expostas de Weinberg e Gould (2006) é possível supor que, sendo as habilidades sociais, em grande parte responsáveis pelo bem-estar psicológico do indivíduo, desenvolvê-las junto aos atletas deverá também aumentar o nível de desempenho da equipe. Consequentemente é possível inferir que as habilidades sociais possam funcionar como ferramenta para uma melhor adaptação às mudanças que o contexto esportivo proporciona, além de facilitar o desenvolvimento pessoal por meio do esporte.

Sobre a construção de um modelo de treinamento de habilidades sociais para atletas, como nada se encontrou na literatura, partiu-se da literatura mais abrangente que trata deste processo de forma generalizada. Del Prette e Del Prette (2005) colocam que as habilidades sociais relevantes em uma intervenção sejam: habilidades sociais de comunicação, civilidade, assertividade, empatia, habilidades sociais de trabalho, habilidades de autocontrole e expressividade emocional, fazer manter amizades, solução de problemas interpessoais e habilidades sociais acadêmicas.

Todas elas parecem úteis aos atletas, indicando assim que um programa voltado para a prática do futebol deva ser composto de forma que proporcione a vivência de todas elas.
Parece apropriado concluir que o comportamento socialmente habilidoso seja um diferencial de grandes esportistas, a competência expressa nas relações com outros atletas, técnicos, dirigentes, empresários, mídia e torcedores, sendo assim o trabalho com o treinamento de habilidades sociais possivelmente ajude no crescimento pessoal e profissional dos atletas.

\section{Objetivo}

Os objetivos deste trabalho foram os de desenvolver a competência social de atletas de um time de futebol e verificar sua relação com o desempenho esportivo da equipe, tendo como hipóteses que o treinamento de habilidades sociais com atletas de futebol aumenta o desempenho esportivo dos mesmos, assim como proporciona o estabelecimento de vínculo entre os atletas e favorece a formação de uma equipe.

\section{Método}

Participantes e local: o programa foi desenvolvido em um Clube de futebol profissional com 20 atletas da categoria juvenil, na faixa etária de 14 a 16 anos, divididos em dois grupos. Enquanto um dos grupos passou pela intervenção, o outro grupo aguardou o seu término e foi contemplado com os mesmos procedimentos posteriormente. Todos os atletas eram estudantes, a maioria morava em alojamento do próprio Clube, uma vez que são originários de outras cidades e os demais residiam em Curitiba com seus familiares.

Instrumentos: com a finalidade de validar o procedimento foi utilizado o seguinte instrumento em pré-teste e pós-teste: Inventário de Habilidades Sociais (IHS), que avalia o nível de habilidades sociais do atleta pré-intervenção e pós-intervenção. Tem características psicométricas avaliadas em população de jovens no fim da adolescência e adultos, tendo sido já objeto de várias pesquisas, inclusive com outros grupos e faixas etárias (com adaptação de alguns itens). Suas principais características: diversidade de situações apresentadas nos itens, coerentemente com o conceito de habilidades sociais, que se agrupam em classes gerais de desempenho indispensáveis para relações satisfatórias e 
bem sucedidas; características psicométricas bastante favoráveis (aprovado pelo Conselho Federal de Psicologia); possui 38 itens e aplicação prevista para no máximo 30 minutos. ${ }^{1}$

Com a finalidade de avaliar as impressões dos participantes sobre as atividades desenvolvidas no programa foi aplicado o Questionário de Avaliação do Programa, o qual foi desenvolvido pelas pesquisadoras. As perguntas envolvem temas que foram trabalhados (conceito e vivências), as habilidades da facilitadora do grupo, bem como o local de aplicação; possui 10 itens e aplicação prevista para no máximo 20 minutos.

Procedimento: para a concretização da pesquisa os vinte atletas que foram indicados pelo Clube para participar assinaram o termo de consentimento e responderam à avaliação no pré-teste individual. Ao término da etapa inicial, foram divididos em dois grupos, escolhidos também pelo Clube, para frequentar o primeiro grupo de intervenção, grupo experimental, restando o grupo controle, que aguardou para receber a mesma intervenção. Ao término das atividades do grupo de intervenção, os dois grupos passaram por reavaliação. 0 grupo 1 , ao terminar a intervenção, além de ser avaliado novamente com o Inventário de Habilidades Sociais também respondeu a um questionário qualitativo (Anexo 1), desenvolvido pela acadêmica, sobre a realização do programa. A identificação de cada atleta ocorreu por meio dos símbolos P1 a P18.

Quatro atletas se desligaram da Instituição antes que o programa de intervenção iniciasse, e, por esta razão, foram excluídos da amostra. Desta forma o primeiro grupo ficou composto de um $\mathrm{N}=9$ atletas e o segundo com um $\mathrm{N}=7$ atletas. Foram 11 encontros com o grupo de intervenção, chamado aqui de experimental, que aconteceram com duas sessões semanais de aproximadamente $1 \mathrm{~h} 30$, totalizando aproximadamente 16 horas, e abordaram-se os temas descritos na Tabela 1.

Tabela 1 - Descrição das sessões, tema abordado, seu objetivo e procedimento

(Continua)

\begin{tabular}{|c|c|c|c|}
\hline Sessão & Habilidade Treinada & Objetivo & Procedimento da Atividade \\
\hline 1 & & Aplicação do inventário. & $\begin{array}{l}\text { Explicar sobre o sigilo da identidade do atleta, bem como o } \\
\text { funcionamento da aplicação do inventário. }\end{array}$ \\
\hline 2 & Autoconhecimento & $\begin{array}{l}\text { Estimular a autopercep- } \\
\text { ção, autoconhecimento } \\
\text { e apresentar-se ao } \\
\text { grupo. Reconhecer as } \\
\text { semelhanças e diferen- } \\
\text { ças entre as pessoas e } \\
\text { melhorar a aceitação de } \\
\text { si e do outro. }\end{array}$ & $\begin{array}{l}\text { Nova identidade: o que são as habilidades sociais e de que } \\
\text { forma elas podem ajudar no bem estar de uma pessoa. Em } \\
\text { seguida, distribuição de revistas, colas, tesouras, e folhas } \\
\text { sulfites. De um lado o atleta deve colar coisas que ele goste, e } \\
\text { do outro lado coisas que ele não goste. Ao fim, reflexão sobre } \\
\text { autoconhecimento. }\end{array}$ \\
\hline 3 & H.S. de comunicação & $\begin{array}{l}\text { Treinar a comunicação } \\
\text { entre os participantes; } \\
\text { ensinar a dar e pedir } \\
\text { feedback. }\end{array}$ & $\begin{array}{l}\text { Objetos iguais (Caldeira, 2007): objetos iguais são dados a } \\
\text { dois participantes, um deles usará os objetos para formar } \\
\text { uma imagem, e o outro sem poder ver, apenas com instruções } \\
\text { verbais deverá realizar a mesma imagem. Os demais ficam como } \\
\text { observadores. Depois da primeira rodada, todos devem passar } \\
\text { pelos } 3 \text { papéis: instrutor, realizador e observador. }\end{array}$ \\
\hline 4 & Contrato & $\begin{array}{l}\text { Realizar o contrato com } \\
\text { o grupo. }\end{array}$ & $\begin{array}{l}\text { Como no primeiro encontro não foi realizado um } \\
\text { contrato, a necessidade do mesmo foi percebida e } \\
\text { resgatada neste encontro. }\end{array}$ \\
\hline 5 & Civilidade e Assertividade & $\begin{array}{l}\text { Diferenciar atitudes as- } \\
\text { sertivas de agressivas e } \\
\text { passivas. Conversar com } \\
\text { autoridade, fazer pedi- } \\
\text { dos, exercitar cidadania, } \\
\text { direitos, argumentar, } \\
\text { defender opinião. }\end{array}$ & $\begin{array}{l}\text { Fazendo pedido ao coordenador (adaptado Del Prette \& Del } \\
\text { Prette, 2005): três duplas foram formadas e receberam um texto } \\
\text { de orientação. Cada dupla recebeu a incumbência de solicitar ao } \\
\text { coordenador providências para solucionar os problemas. Após } \\
\text { a última comissão se apresentar, foi solicitado que os atletas } \\
\text { escolhessem aquela que deveria representar a todos. } \\
\text { Ao fim, reflexão sobre a postura passiva, agressiva e assertiva. }\end{array}$ \\
\hline
\end{tabular}

1 Disponível em: <http://www.rihs.ufscar.br/index.php?option=com_content\&task=view\&id=32\&Itemid=42>. Acesso em: 25 jun. 2009. 
Tabela 1 - Descrição das sessões, tema abordado, seu objetivo e procedimento

(Conclusão)

\begin{tabular}{|c|c|c|c|}
\hline Sessão & Habilidade Treinada & Objetivo & Procedimento da Atividade \\
\hline 6 & Empatia & $\begin{array}{l}\text { Desenvolver empatia e } \\
\text { fair-play no futebol. }\end{array}$ & $\begin{array}{l}\text { O desenho do outro em minha folha (Hauer, 2006): cada par- } \\
\text { ticipante recebeu uma folha sulfite, um lápis e uma ficha com } \\
\text { o nome de um objeto. Cada um deveria desenhar na folha } \\
\text { que recebeu seu objeto. Após todos terminarem, indicou-se } \\
\text { que eles deveriam passar a sua folha para o companheiro ao } \\
\text { lado e desenhar o seu objeto na folha alheia. Isso se repetiu } \\
\text { até que todos os objetos fossem desenhados em todas as folhas. } \\
\text { Ao fim foi realizada uma reflexão da empatia no futebol. }\end{array}$ \\
\hline 7 & Empatia & Desenvolver empatia. & $\begin{array}{l}\text { Zezinho (adaptado de Del Prette \& Del Prette, 2001): Foram } \\
\text { formados três duplas, cada um recebeu um trecho da estória } \\
\text { de Zezinho (sem saberem que os trechos que cada um } \\
\text { recebe é da mesma história), deveriam dar suas opiniões } \\
\text { a respeito do que acham que o Zezinho é, o que faz, o que } \\
\text { gosta. Após todos receberem todos os trechos é realizada a } \\
\text { leitura do texto inteiro e uma reflexão a respeito. }\end{array}$ \\
\hline 8 & Empatia & Desenvolver empatia. & $\begin{array}{l}\text { Filme “Duelo de Titãs”: Passar o filme “Duelo de Titãs”, e ao fim } \\
\text { fazer reflexão sobre a função da empatia neste caso para a vitória. }\end{array}$ \\
\hline 9 & Expressividade Emocional & $\begin{array}{l}\text { Identificar sentimentos } \\
\text { localizá-los, falar de si, } \\
\text { favorecendo o autoco- } \\
\text { nhecimento. }\end{array}$ & $\begin{array}{l}\text { "O que você sente" (Rocha, 2008): apresentar aos atletas } \\
\text { diferentes imagens e solicitar que escrevam o que cada uma } \\
\text { os faz sentir. } \\
\text { e “Os sentimentos tem cores" (adaptado de Heegaard, } \\
\text { 1998): que solicita ao participante que localize onde em seu } \\
\text { corpo sente os sentimentos de: tristeza, medo, raiva, culpa, } \\
\text { ciúmes, nervosismo e alegria. }\end{array}$ \\
\hline 10 & Resolução de Problemas & $\begin{array}{l}\text { Estimular a reflexão } \\
\text { sobre a maneira com que } \\
\text { encaram os problemas. }\end{array}$ & $\begin{array}{l}\text { "Construção Impossível” (Rocha, 2008): solicitar aos par- } \\
\text { ticipantes que, em grupo, montem a maquete da Arena da } \\
\text { Baixada completa, o mais parecido possível, com detalhes. } \\
\text { Explicar que eles só podem utilizar o material disponível e } \\
\text { têm o tempo de } 1 \text { h20 para montagem, restando ainda ao fim } \\
\text { um tempo para realizarem discussão e reflexão da atividade. }\end{array}$ \\
\hline 11 & & Aplicação do inventário. & Aplicação coletiva em decorrência do tempo. \\
\hline
\end{tabular}

Fonte: Dados da pesquisa.

\section{Resultados e discussão}

Quanto à frequência dos participantes nas atividades é importante registrar que apenas P2, P4 e P6 estiveram presentes em todos os encontros. As faltas, em sua maioria, ocorreram por problemas físicos dos atletas que necessitavam de atendimento especializado, no contra turno de seus treinos, o que coincidia com o horário de funcionamento das atividades do programa.

Esse fato está em concordância com a afirmação de Weinberg e Gould (2006) de que para técnicos e atletas uma das razões para negligenciar a preparação psicológica é o tempo, uma vez que consideram o próprio tempo de treinamento físico reduzido. Desta forma são priorizadas as atividades ligadas diretamente ao desempenho físico, tais como o próprio treino físico, sessões de fisioterapia e musculação.
Para avaliar o nível de habilidades sociais dos atletas foi utilizado o Inventário de Habilidades Sociais, de Del Prette e Del Prette (2001). No pré-teste a maior parte $(\mathrm{N}=9)$ dos participantes teve seus escores totais na faixa de interpretação bom repertório, destacando-se positivamente $\mathrm{P} 9, \mathrm{P} 12$ e P15 que obtiveram escore geral indicativo bastante elaborado. Já os participantes P1, P7 e P16 obtiveram escores indicativos de habilidades totais abaixo da média inferior.

Comparando os resultados totais do pré e do pós-teste foi possível verificar que cinco dos participantes (P1, P2, P3, P6 e P7) obtiveram um aproveitamento significativo do programa, elevando seu escore de categoria, sendo que P1 e P7 passaram de abaixo da média inferior para bom repertório, já P2, P3 e P6 tinham um bom repertório e foram para altamente elaborado. Sendo assim, o programa de 
habilidades sociais desenvolvido teve como resultado um aumento acentuado dos domínios propostos, ou seja, das habilidades sociais, como ilustra a Figura 1.

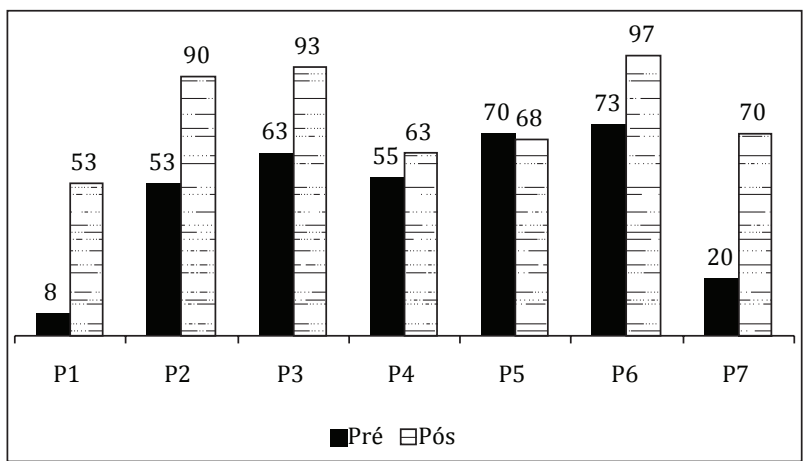

Figura 1 - Avaliação do Escore Total do IHS, no pré e pós-teste, dos atletas participantes do grupo de intervenção

Fonte: Dados da pesquisa.

P4 e P5 enquadravam-se na categoria bom repertório na avaliação pré-teste e mantiveram-se nela no pós-teste, com a diferença que $\mathrm{P} 4$ aumentou em 8 pontos percentílicos seu escore e P5 teve seu escore diminuído em 2 pontos percentílicos. Infere-se que esta queda de escore seja decorrente da ausência de P5 em quatro encontros, sendo três faltas seguidas, pois sofreu uma lesão durante o programa. Além disso, a responsável social dos atletas informou que P5 tem um perfil de comportamento tímido e que sua mãe e a própria assistente social temem que isto o atrapalhe em sua carreira profissional. A timidez é muitas vezes produto de inibição coercitiva com várias origens (Mestre \& Corassa, 2000; Sidman, 2003). Pelo exposto, as pesquisadoras entenderam que possivelmente P5 necessite de um acompanhamento diferenciado para desenvolver ainda mais suas habilidades.

0 IHS é subdivido em 5 fatores, o primeiro deles diz respeito às habilidades de enfrentamento e autoafirmação, ou seja, o desempenho em situações que envolvem riscos, afirmação e defesa dos direitos; a autoafirmação está ligada à autoestima, assertividade e controle da ansiedade.

Neste fator destacou-se o P7 pela desenvoltura das habilidades enquadradas no Fator 1, uma vez que atingiu uma pontuação $63 \%$ maior no pós-teste, deixando a categoria médio inferior para bastante elaborado. 0 mesmo aconteceu para P6, que tinha um escore de 63 e chegou a 83\%. P1, P2 e P3 foram avaliados inicialmente como tendo um repertório médio inferior e passaram a ter um bom repertório, com melhora de 30\%, 30\% e 45\% respectivamente. P5 manteve-se na categoria médio inferior, pois aumentara apenas 5\% em relação ao primeiro teste.

A análise desta categoria, chamada de Enfrentamento e Autoafirmação Com Risco, avaliou os dados de tomada de iniciativa e enfrentamento que estão diretamente ligados à autoafirmação e a autocompetência. Por meio desta categoria é possível verificar o proposto por Guilhardi (2002), ao dizer que os sentimentos, como comportamento que são, sofrem as consequências das contingências. Quanto mais diferenciadas as respostas de autocompetência que um indivíduo adquirir, provavelmente melhores consequências suas respostas obterão e consequentemente serão reforçados comportamentos associados à coragem e autodeterminação.

Sendo assim, comparando-se os escores do Fator 1 em pré e pós-teste é possível inferir a eficiência nas atividades propostas pelo programa, uma vez que em sua maioria os participantes apresentaram melhoras significativas, ou seja, subiram de categoria de desempenho (mesmo mantendo-se na mesma P5 teve melhora de desempenho nas subclasses).

Os resultados obtidos em relação ao fator 2 , Autoafirmação na expressão de sentimentos positivos, que envolvem expressão de sentimentos e consequente autoafirmação da autoestima, mostraram que P7 obteve o maior índice de aproveitamento, com uma melhora de $40 \%$ em relação ao seu pré-teste, alterando sua categoria de bom repertório para repertório bastante elaborado. Mudaram de categoria também P1 e P6. 0 primeiro tinha um repertório abaixo da média inferior, e passou a ter um bom repertório. P6 passou de bastante elaborado para altamente elaborado. Mantiveram-se na mesma categoria P2, P3 e P4, sendo elas: altamente elaborado, bom repertório e bastante elaborado, respectivamente. P5 novamente apresentou queda de escore, passando do índice 93 para 88, o que representou alteração de categoria, antes altamente elaborado para bastante elaborado.

Quanto aos escores do Fator 3, Habilidades de Conversação e Desenvoltura Social, P2, P5 e P6 chegaram à classificação de altamente elaborado. Sendo que P6 apresentou neste fator o maior percentual de aprimoramento de habilidades do programa todo, com 70\% em relação ao seu pré-teste. É importante ressaltar que este também foi o único fator em que P5 obteve melhora de escore, passando de 42,5\% 
para 92,5\%. Lembrando que esse foi o atleta que a assistente social do CAPA havia pedido um "olhar especial", graças ao excesso de timidez. Dois atletas (P1 e P7) tiveram um declínio de categoria, P1 e P7 passaram a ter um repertório abaixo da média inferior.

Pode-se levantar a hipótese de que P7 tenha diminuído seu escore em comunicação como reflexo do trabalho com autocontrole, pois P7 revelou-se durante os encontros como uma pessoa explosiva, principalmente em campo, o que o deixava chateado consigo mesmo. Talvez o trabalho de comunicar-se de forma diferente, assertivamente e não agressivamente, tenha sido insuficiente para mudança deste participante, que diante da sensibilização realizada nos encontros, passou a perceber-se mais (autoconhecimento) e como forma de preservar-se tenta ir para o lado mais inassertivo, diminuindo o grau de comunicação.

0 resultado obtido com as vivências de habilidades sociais do quarto fator, Autoexposição a desconhecidos ou a situações novas, revelou que P1 e P4 foram os participantes que mais otimizaram seus escores, passando de 12,5 para 67,5 e 17,5 para 57,5 respectivamente, o que representa mudança da categoria abaixo da média inferior para bom repertório. 0 mesmo ocorrendo com P4. Já os participantes P6 e P7 tinham um repertório médio inferior e seguiram para bom repertório e bastante elaborado, respectivamente com $20 \%$ e $45 \%$ de melhora em relação à primeira aplicação. P2 e P3 mantiveram-se em suas classes anteriores, bastante elaborado e médio inferior. Já P5 sofreu queda 40\% em relação o pré-teste, o que o levou de um repertório bastante elaborado para bom repertório.

Com relação ao fator 5, Autocontrole $d a$ Agressividade, ou seja, expressar o desagrado e a raiva de forma socialmente competente, a maioria dos participantes diminuíram seus escores no pós-teste, com duas exceções: P6 que manteve o mesmo escore e categoria, e P3 que apesar de aumentar seu percentual, manteve-se também na mesma classe, bom repertório. Apesar da diminuição de escores apenas P2, P5 e P7 abaixaram sua classificação qualitativa. P2 passou de altamente elaborado para bom repertório; $\mathrm{P} 5$ de médio inferior para abaixo da média inferior e P7 de bom repertório para abaixo da média inferior.

As pesquisadoras interpretaram que possivelmente a desenvoltura e o autoconhecimento atingido durante o programa tenham propiciado aos atletas uma maior percepção de suas atitudes como agressivas.
Caso esta hipótese seja verdadeira, ao discriminarem suas formas de interação, se tornaram mais aptos a contracontrolar eficientemente com repertório alternativo à agressão, situações as quais, anteriormente, reagiam com agressividade (Sidman, 2003). Ou seja, ao perceber como se comporta e a relação deste comportamento com as variáveis ambientais, o indivíduo terá mais probabilidade de controlar seu comportamento.

Weinberg e Gould (2006, p. 496) expõem que existem dois tipos de agressões, a hostil e a instrumental, sendo esta última a mais comum em esportes. Tomam como agressão instrumental aquela que

...ocorre na busca de algum objetivo não agressivo [...] um zagueiro provocar uma colisão particularmente dura com um receptor para impedi-lo de receber um passe e correr pelo meio do campo. [...] Os profissionais da ciência do esporte e do exercício devem ter uma filosofia que seja muito bem refletida quanto ao que é comportamento assertivo aceitável e comportamento agressivo instrumental inaceitável.

Também foi levantada a hipótese de que durante o Programa de Habilidades Sociais para o Futebol não foi promovida de forma suficiente esta reflexão com os participantes, da distinção desta agressividade permitida dentro do contexto esportivo e da agressividade exacerbada, que precisa ser autocontrolada para que não se torne aversiva para o próprio atleta.

Já foi citado que enquanto um grupo passava pela intervenção, outro aguardava sem atividades do mesmo tipo. Assim que se encerraram as atividades do grupo experimental, os instrumentos de aferição de habilidades sociais foram novamente aplicados. A Figura 2 compara a média de pontos percentílicos de habilidades sociais dos dois grupos (experimental e controle) no pré e pós-teste.

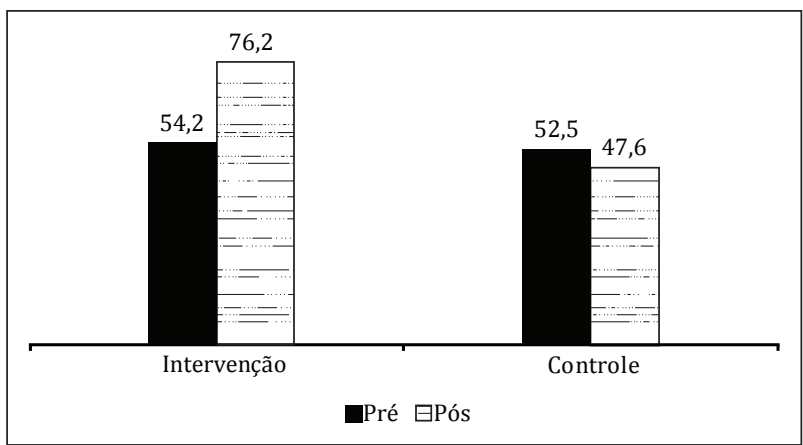

Figura 2 - Média dos escores totais do Inventário de Habilidades Sociais dos atletas participantes dos dois grupos, no pré e pós-teste Fonte: Dados da pesquisa. 
Percebe-se que a média dos escores totais de HS no grupo de intervenção foi de 54,2 pontos percentílicos, e no grupo controle, de 52,5 no pré-teste. Ou seja, os dois grupos não possuíam diferença significativa em relação às suas habilidades totais.

Na Figura 2 também é possível observar o aumento significativo das habilidades sociais entre o pré e o pós-teste para os participantes do grupo de intervenção. A média de escores totais aumentou em 22 pontos percentis. Quanto aos atletas do grupo controle (que ainda não havia passado por intervenção), entre o pré-teste 1 e o pós-teste, ocorreu declínio de 4,9 pontos percentis no escore médio de habilidades sociais. Totalizando no pós-teste uma média de 76,2 e 47,6 percentis respectivamente.

Em uma análise geral pode-se dizer que o grupo de atletas selecionados para participar da pesquisa mostrou aumento em suas habilidades sociais, mais acentuado nos participantes do grupo 1, que sofreu a intervenção antes (os participantes P8, P9 e P15 foram retirados desta análise por não terem realizado o pós-teste).

Importante notar que em ambos os grupos existiam participantes classificados como repertório abaixo da média inferior e bastante elaborado, tal fato possibilitou verificar aquilo que Skinner (1978) fala sobre generalização de respostas e diferenciação de resposta, que refere-se ao reforçamento de um comportamento provocar no ambiente as mudanças de contingências, ou seja, o atleta que possui o comportamento habilidoso, participando do grupo, é reforçado a manter seu comportamento, e aquele que é inábil poderá ter o colega como modelo para o aperfeiçoamento de sua habilidade, o que permite que o teto de razão de cada participante se eleve e assim, aprimorando a performance do grupo, não só esportiva, como das áreas pessoais.

Partindo do pressuposto que no contexto do Clube existem atletas com alto nível operante em habilidades sociais, ao se trabalhar um grupo e sensibilizá-lo com o tema, transformam-se as contingências e aumentam-se as possibilidades dos demais atletas, que aguardam o término do primeiro grupo de intervenção, a apresentarem respostas diferenciadas, positivamente, em relação às habilidades sociais.

Skinner (1978, p. 286) postula que "o comportamento do indivíduo explica o fenômeno do grupo" pois, uma ação social é motivada por comportamentos dos indivíduos em prol de um ambiente comum.
Quanto ao questionário de avaliação, foi possível levantar que em relação ao tema Habilidades Sociais apenas um participante não soube dizer se o tema abordado seria importante para o atleta. Todos os demais colocaram que concordam totalmente ou apenas concordam com a importância deste assunto. Todos avaliaram que o programa contribuiu para seu desenvolvimento pessoal e grande parte considera a contribuição também para o desempenho esportivo. Segundo os mesmos, o tema que mais ajudou foi: autoconhecimento, comunicação, expressão de sentimentos e empatia.

A partir do exposto é possível dizer que os atletas, ao se submeterem ao Inventário de Habilidades Sociais, novamente estariam sob o controle mais eficaz dos próprios estímulos do autoconhecimento, possivelmente, graças à participação direta com o grupo de intervenção e indireta deste em seu meio ambiente.

De acordo com os dados levantados e com a análise ocorrida foi possível perceber que as habilidades sociais em geral aumentaram significativamente no grupo de intervenção.

\section{Conclusão}

O desenvolvimento de um programa de habilidades sociais para o futebol mostrou-se eficaz em potencializar comportamentos dos atletas para serem mais habilidosos em suas relações interpessoais.

Há indícios também de que os atletas que têm mais competência social, ou seja, que conseguem efetivamente agir de acordo com as habilidades sociais que possuem (Del Prette \& Del Prette, 2001), têm maior possibilidade de enfrentar situações estressoras e interpretá-las como contingências de um atleta inserido no contexto esportivo, que são possíveis de serem avaliadas positivamente e transformá-las em algo que some ao seu desempenho, como situações de aspecto de jogo, avaliadas unanimemente pelos atletas do primeiro grupo, como sendo positivas.

Utilizando a avaliação em pré-teste, bem como a avaliação de cada encontro, foi possível estruturar e adaptar o programa para suas demandas específicas, ou seja, de acordo com as necessidades de cada participante.

A partir dos resultados gerais é possível definir que para próximos grupos, duas outras competências sejam mais trabalhadas, que são a comunicação assertiva e autocontrole da agressividade. 
Sendo assim, é possível estabelecer que o processo de comunicação em uma competição esportiva forma um sistema integrado de interação e reação. Entendendo-se a comunicação como "responsável pela formação de extensas redes de troca social que mantêm e alteram a cultura e, consequentemente, a realidade social" (Del Prette \& Del Prette, 2001, p. 64), e verificando que esta é uma competência importante diante de um esporte coletivo, como asseveram Samulski e Lopes (2009). Estes afirmam que a comunicação influencia a motivação, concentração, estratégia, aquisição de novas habilidades, sentimentos, pois é a ferramenta que indivíduos têm para compartilhar. Desta forma parece ser de fato importante estabelecer mais vivências para que se propicie um maior aproveitamento dos atletas.

Dentro das limitações do estudo, coloca-se a necessidade de que nas próximas experiências seja realizada a explicação e reflexão com os atletas sobre este aspecto, ajudando-os a definir situações e formas de controlar sua agressividade, de modo que esta o ajude em seu desempenho e não o atrapalhe. Lembrando Weinberg e Gould (2006) ao colocar que a agressividade instrumental pode ser benéfica para o atleta, principalmente em esportes de contato, como é o caso do futebol.

0 aumento de escore das habilidades sociais não pode ser comparado com um possível aumento do desempenho esportivo, uma vez que não há nenhum instrumento que valide essa hipótese, a única avaliação que se tem com relação ao aumento do desempenho esportivo é a autoavaliação dos participantes no Questionário de Avaliação Qualitativa, em que cinco participantes relataram que a participação no programa os auxiliou também neste sentido.

A continuidade deste trabalho ou a inserção da mesma, em categorias de base, e até mesmo nas categorias principais, pode ser de alguma valia, se adaptada à realidade dos times. Preece e Mellor (2008, p. 88) apontam que os participantes de programas de habilidades sociais que obtiveram algum progresso durante, ao receberem um acompanhamento contínuo podem aumentar o seu benefício.

Entende-se que contatos posteriores com participantes desta atividade possam fornecer dados sobre a continuidade dos mesmos no esporte e até mesmo se eles atribuem que, graças ao grupo, suas relações interpessoais foram aprimoradas e consequentemente refletiram de forma positiva sobre o desempenho atlético.

\section{Referências}

Brandão, M. R. (2004). Ciência do futebol organizado por Barros e Guerra. Barueri: Manole.

Boaz, Y. (2000). Duelo de Titãs. EUA: Walt Disney Pictures.

Caldeira, M. F. (2007). Psicologia clínica. Comunicação Pessoal.

Campos, R. S. (2004). Estudo comparativo das habilidades motoras e cognitivas em praticantes de futebol de diferentes locais de prática. Tese de Mestrado em Educação Física, no Departamento de Educação Física, Setor de Ciências Biológicas da Universidade Federal do Paraná, Curitiba.

Corrêa, D. K. A. (2004). A construção de competências coletivas em equipes esportivas: 0 caso do futebol. Dissertação de Mestrado em Administração da Universidade Federal do Rio Grande do Sul, Porto Alegre.

Del Prette, A., \& Del Prette, Z. A. P. (2001). Psicologia das relações interpessoais e habilidades sociais: Vivências para o trabalho em grupo. Petrópolis: Vozes.

Del Prette, A., \& Del Prette, Z. A. P. (2005). Psicologia das habilidades sociais na infância: Teoria e prática. Petrópolis: Vozes.

Dereli, E. (2009). Examining the permanence of the effect of a social skills training program for the acquisition of social problema-solving skills. Social Behavior and Personality, 37(10), 1419-1428.

Gaspar, T., Matos, M. G., Ribeiro, J. L. P., \& Leal, I. (2006). Qualidade de vida e bem-estar em crianças e adolescentes. Revista Brasileira de Terapias Cognitivas, 2(2), 47-60.

Gresham, F. M. (2002). Bestpractices in social skills training. In A. Thomas \& J. Grimes (Ed.). Best practices in school psychology (pp. 1029-1040). Washington: National Association of School Psychologists.

Gresham, F. M., Cook, C. R., Hern, L., Barreras, R. B., Thornton, S., \& Crews, S. D. (2008). Social skills training for secondary students with emotional and/ or behavioral disorders. Journal of Emotional and Behavioral Disorders, 16(3), 131-144. 
Guilhardi, H. J. (2002). Autoestima, autoconfiança e responsabilidade. In Z. Brandão. Comportamento humano. Campinas: ESETec. Recuperado em 15 maio 2008, em http://www.terapiaporcontingencias.com. br/pdf/helio/Auto_estima_e_autoconfianca_sao_metafor as2007.pdf

Harrell, A. W., Mercer, S. H., \& DeRosier, M. (2009). Improving the social-behavioral adjustment of adolescents: The effectiveness of a social skills group intervention. Journal of Family Studies, 18, 378-387.

Hauer, A. J. (2006). Dinâmica de grupo e relações humanas. Comunicação Pessoal.

Heegaard, M. (1998). Quando a família está com problemas. Porto Alegre: Artmed.

Howie, L. D., Lukacs, S. L., Pastor, P. N., Reuben, C. A., \& Mendola, P. (2010). Participantion in activities outside of school hours in relation to problem behavior and social skills in middle childhood. Journal of School Health, 80(3), 119-125.

Mestre, M., \& Corassa, N. (2000). Da ansiedade à fobia. Psicologia Argumento, 18(26), 105-126.

Moreno, J. C. (2007). Relações interdisciplinares entre jogos tradicionais, educação, lazer e educação física. Revista Fafibe On Line, n. 3, 2007. Recuperado em 15 maio 2008, em www.fafibe.br/revistaonline

Oliveira, E. Z. (2005). Psicologia das habilidades sociais na infância. Teoria e Prática Revista Avaliação Psicologica, 4(1), 91-93.
Preece, S., \& Mellor, D. (2008). Learning patterns in social skills training programs: An exploratory study. Child and Adolescent Social Work Journal, 26(2), 87-101.

Rocha, G. V. M. (2008). Habilidades sociais. Comunicação pessoal.

Samulski, D., \& Lopes, M. L. (2009). Comunicação no esporte In D. Samulski. Psicologia do esporte: Conceitos e novas perspectivas (pp. 335-356). Barueri: Manole.

Samulski, D., \& Parreiras, L. A. M. (2009). Personalidade. In D. Samulski. Psicologia do esporte: Conceitos e novas perspectivas. (pp. 35-56). Barueri: Manole.

Sidman, M. (2003). Coerção e suas implicações. Campinas: Livro Pleno.

Skinner, F. B. (1978). Ciência e comportamento humano. São Paulo: M. Fontes.

Soto, L. F. (2000). El juego: Una propuesta metodológica activa. Revista Digital Efdeportes, 5(22). Recuperado em 21 maio 2000, em http://www. efdeportes.com/efd22/eljuego.htm

Weinberg, R. S., \& Gould, D. (2006). Fundamentos da psicologia do esporte e do exercício ( $2 \mathrm{a}$ ed). Porto Alegre: Artmed. 


\section{Anexo I - Questionário de Avaliação do Programa}

Nome:

O objetivo deste questionário é levantar a opinião dos participantes do grupo de Habilidades Sociais com relação à forma como as atividades conduzidas pela acadêmica valeram para sensibilizar sobre o tema proposto bem como outras questões referentes a opinião do programa aplicado. Agradeço a sua participação, sem ela, este projeto não seria realizado!

Não há respostas certas ou respostas erradas, o importante é que você consiga responder sinceramente o que achou com relação a cada coisa que será solicitada sua opinião. Assegura-se que os dados serão tratados sigilosamente pelo código de ética, ou seja, não é necessário se preocupar com que suas respostas sejam divulgadas com sua identificação.

Este programa foi realizado pela aluna do 5o ano de Psicologia da Faculdade Evangélica do Paraná: Mariana Monteiro (100600052)

Professora responsável: Dra. Giovana Veloso Munhoz da Rocha

\section{Esta é a legenda para as questões da próxima folha:}

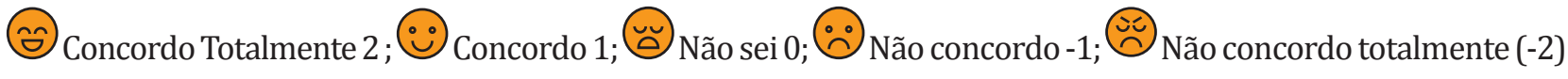

O tema Habilidades Sociais é importante para o atleta.

Esta atividade contribuiu para o seu desenvolvimento pessoal.

Esta atividade contribuiu para o seu desempenho esportivo.

Você aprendeu o que são e para que servem as habilidades sociais.

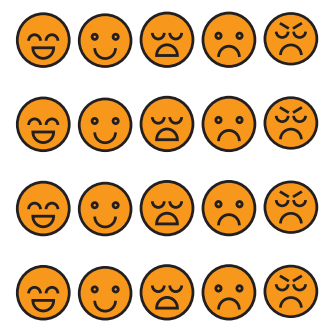

Os temas abordados (autoconhecimento, comunicação, assertividade, empatia, expressão de sentimentos, resolução de problemas) ajudaram você?
Autoconhecimento

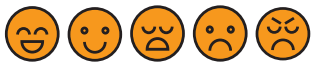
Comunicação

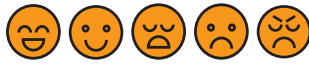
Assertividade
Empatia
Expressão de sentimentos
Resolução de problemas

A coordenadora das atividades ajudou você a entender e aprender sobre o assunto.

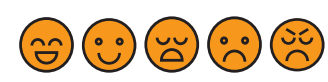

A Ilha (local onde nos encontramos) foi um lugar adequado para falar sobre o tema e realizar as atividades.

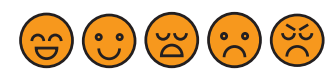

Qual dia ou atividade você gostou mais de participar?

Qual atividade você menos gostou?

Ok, agora você tem um espaço para dar o seu feedback geral sobre o programa de habilidades sociais, pode ser uma mensagem, crítica, elogio, sugerir alguma coisa para ajudar a melhorar cada vez mais! 